\title{
The potential of milk fat for the synthesis of valuable derivatives
}

\author{
Marta Lubary · Gerard W. Hofland · Joop H. ter Horst
}

Received: 27 August 2010 / Revised: 18 October 2010 / Accepted: 26 October 2010 / Published online: 16 November 2010

(C) The Author(s) 2010. This article is published with open access at Springerlink.com

\begin{abstract}
The overall decline in milk fat consumption experienced in the last decades has promoted global research efforts seeking for alternate uses of this valuable natural fat. Milk fat possesses a pleasant flavor and a rich chemical composition, including a range of bioactive, health beneficial minor components. The main drawbacks of milk fat from the consumer point of view are its poor spreadability at refrigeration temperature and its high content in saturated fatty acids, which raises health concerns. However, the rich fatty acid composition of milk fat could be utilized for the production of a wide range of added-value derivatives in the food and cosmetic industries, including nutritionally enhanced modified fats, food emulsifiers, flavors, and tailor-made lipids. A promising strategy for the revalorization of milk fat encompasses the isolation and commercialization of the valuable minor components of milk fat, coupled with a broader utilization of physically or nutritionally improved milk fat fractions and derivative products.
\end{abstract}

Keywords Milk fat $\cdot$ Butter $\cdot$ Revalorization $\cdot$ Short-chain fatty acids $\cdot$ Milk fat engineering $\cdot$ Conjugated linoleic acid

\section{Introduction}

Milk from livestock has traditionally been an important element of the human diet. Milk is composed of a balanced amount of fat, protein, sugars, vitamins, and minerals [1,2].

M. Lubary $(\varangle) \cdot$ J. H. ter Horst

Department of Process and Energy,

Delft University of Technology, Leeghwaterstraat 44,

2628 CA Delft, The Netherlands

e-mail: marta.lubary@gmail.com

G. W. Hofland

Feyecon Development and Implementation,

Rijnkade 17a, 1382 GS Weesp, The Netherlands
The fat component of milk has been used for centuries to produce valued and nutritious food products such as butter, cream, and cheese $[1,3]$.

Milk fat has a complex and rich chemical composition. Its unique sensorial properties (flavor and mouthfeel) have been much appreciated historically, and its consumption was traditionally recommended [4] and associated with high living standards [3]. However, the consumption of milk fat in developed countries has been declining for the last decades, with a remarkable shift occurring since the 1980s due to the strong commercialization of margarines. The main reasons for this trend were evaluated in a US survey to be the following [3]:

- Price: milk fat is relatively expensive, unable to compete with vegetable oils as a food ingredient.

- Health image: its high content in saturated fatty acids and cholesterol is believed to increase the risk of coronary diseases and obesity.

- Limited functionality: due to its high solid fat content at refrigeration temperature, butter is poorly spreadable.

- Little product innovation and poor advertisement, in comparison with vegetable oil-based products.

The consumption decline of milk fat has led to the accumulation of milk fat stocks worldwide, which prompted global research efforts for the development of alternative uses of milk fat as a feedstock for added-value products [1, 5-7]. The current situation of the European milk fat market as well as the existing research trends and opportunities for milk fat revalorization is reviewed and discussed in this paper.

\section{The dairy sector}

Anhydrous milk fat (AMF) manufacture generally serves as a "safety valve" for the dairy industry [3], as it absorbs 
excess milk supply above market requirements for other dairy products. Surplus milk is skimmed and the cream is converted consecutively to butter, butteroil, and AMF, as shown in Fig. 1. The skimmed milk is dried to produce skimmed milk powder (SMP). Upon a sudden shortage of milk supply for the manufacture of dairy products, stock AMF and SMP can be recombined and processed into the demanded products. However, even with a stationary milk supply, AMF tends to accumulate due to the imbalance between the market demands for low-fat and fat-rich products.
The European Union is a major world dairy producer [8]. About 135 million tons of dairy products are produced annually in the 27 member states of the European Union (EU-27), mostly for internal consumption (Table 1) [9, 10]. About $16 \%$ of the milk produced in EU is used for butter manufacture. Milk production is regulated by a quota system, implemented in 1984 in the frame of the Common Agricultural Policy (CAP). The quota is an effective limit on the amount of milk that dairy farmers produce every year [9], which prevents dairy overproduction and guarantees a minimum selling price of dairy products.
Fig. 1 Dairy production scheme. Adapted from [9]

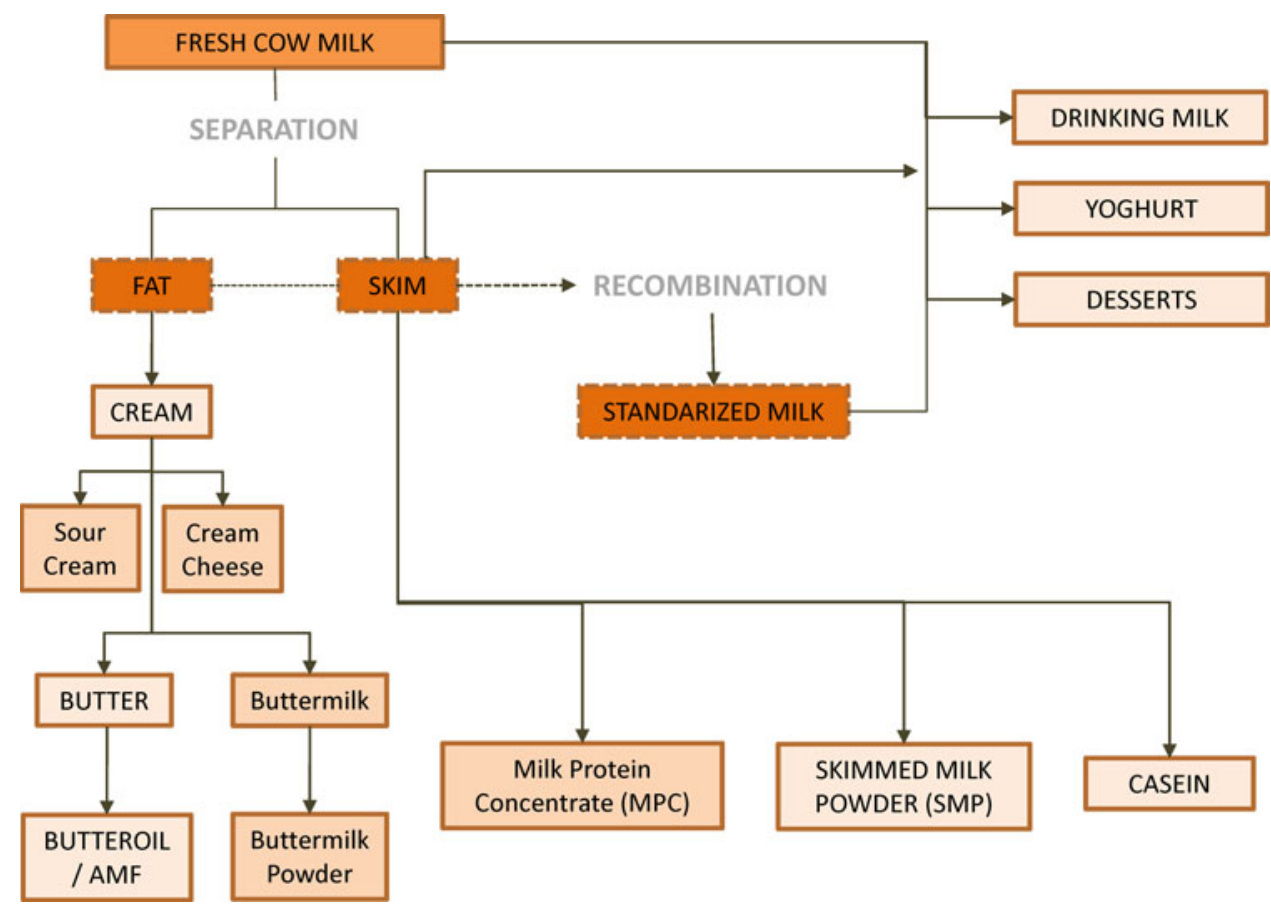

Table 1 Summary of the dairy market balances in the European Union, between 2004 and 2010 [10]

\begin{tabular}{|c|c|c|c|c|c|c|c|}
\hline \multirow[t]{3}{*}{$(' 000 \mathrm{t})$} & \multicolumn{7}{|c|}{ EU Market balances } \\
\hline & 2004 & 2005 & 2006 & $2007^{\mathrm{a}}$ & $2008^{\mathrm{a}}$ & $2009^{b}$ & $2010^{b}$ \\
\hline & EU-25 & EU-25 & EU-25 & EU-27 & EU-27 & EU-27 & EU-27 \\
\hline Milk deliveries & 130,383 & 131,421 & 130,654 & 133,600 & 134,200 & 134,200 & 134,600 \\
\hline Liquid milk production & 33,436 & 33,070 & 33,200 & 33,500 & 33,500 & 33,500 & 33,500 \\
\hline Cheese & 8,685 & 8,850 & 8,960 & 9,200 & 9,250 & 9,270 & 9,400 \\
\hline SMP & 1,080 & 1,110 & 980 & 1,040 & 1,010 & 1,150 & 1,080 \\
\hline \multicolumn{8}{|l|}{ Butter } \\
\hline Production & 2,112 & 2,150 & 2,040 & 2,050 & 2,050 & 1,990 & 1,920 \\
\hline Imports & 89 & 90 & 90 & 85 & 60 & 60 & $60+80^{c}$ \\
\hline Exports & 344 & 330 & 240 & 205 & 140 & 140 & 150 \\
\hline Consumption & 1,937 & 1,950 & 1,930 & 1,930 & 1,910 & 1,890 & 1,910 \\
\hline Stock change & -80 & -40 & -40 & 0 & 60 & 20 & 0 \\
\hline
\end{tabular}

$E U-25$ Data from the 25 member states of the European Union (2004-2007), EU-27 Data from the 27 member states of the European Union (from 2007), SMP skimmed milk powder, ${ }^{\mathrm{a}}$ Data including estimates, ${ }^{\mathrm{b}}$ Data including forecasts. ${ }^{\mathrm{c}}$ Amount proceeding from intervention 
The EU is a major exporter of dairy commodities (butter, cheese, and milk powder), together with New Zealand and Australia [8]. The EU's world export share of butter was $39 \%$ in 2004 . However, as the EU market price for dairy products is higher than the world price (because other major exporters produce at lower costs), exports generally take place with the support of subsidies [9].

Subsidized exports are one of the means to absorb excess butter and AMF. Other measures are aids for private storage, public intervention (purchase of surplus by the government at a set price), and internal disposal in the EU market [9]. Through the schemes for internal disposal, excess butter is given to non-profit organizations or sold at reduced prices for commercial pastry and ice-cream manufacture in competition with vegetable fats [3, 9]. The amount is significant: in 2004, 600,000 tonnes of butter was disposed in this way [9].

Table 1 shows the European market balances for milk and dairy production between 2004 and 2010, including more detailed information for butter products [10]. Although butter stocks completely disappeared in 2007 and again in 2010 (forecasted data) as a result of the abovementioned measures, stocks are still estimated to be accumulated in 2008 and 2009. This could be a result of several factors, including a decrease in butter consumption and the elimination of export subsidies in mid-2007.

The 2003 Common Agricultural Policy reform aims to the deregulation of the dairy sector by gradually reducing export subsidies and intervention on dairy commodities. The quota system is planned to disappear by March 2015 $[9,10]$. The final objective is to accomplish a self-regulated milk supply according to market demands and to align the EU milk prices with global prices. It can be foreseen that further accumulation of butter products can be an immediate consequence of the new policies. New solutions should be found for increasing milk fat consumption and for avoiding losses derived from butter disposal at prices below production costs.

In the following paragraphs, a review of the composition and potential of milk fat for the manufacture of added-value derivatives that can contribute to improve the current situation of the butter market is presented.

\section{The potential of milk fat}

\section{Milk fat composition}

Milk fat is present in bovine raw milk in concentrations of about 3.5-5 wt $\%[11,12]$. It is found in the form of small globules of a diameter $0.1-15 \mu \mathrm{m}$, coated with a membrane derived from the secreting cells [13]. About 98\% of milk lipids are triacylglycerols, glycerol molecules esterified to three fatty acids of variable chain length and saturation degree.

Many volatile and non-volatile compounds contribute to the unique flavor of milk fat, including lactones, ethyl esters, ketones, aldehydes, diacetyl, dimethyl sulfide, and free fatty acids. In addition, milk fat contains fat-soluble vitamins A, D, and E and cholesterol (0.2-0.4\%). The overall composition of milk fat is significantly affected by the cow breed, the cow diet, stage of lactation, and the season $[2,3,5]$. Average values are summarized in Table 2 .

The triacylglycerol composition of milk fat is the most complex from all edible fats [3, 11]. More than 100 different fatty acids have been identified, from which about 11 constitute the vast majority (Table 3) [11]. On average, milk fat contains $20 \mathrm{~mol} \%$ short-chain fatty acids (C4-C10). Over $70 \%$ of the total fatty acids are saturated. Milk fat contains a very small amount of polyunsaturated fatty acids, yet it is the richest natural dietary source of conjugated linoleic acid (CLA). CLA, which is a group of positional isomers of linoleic acid (C18:2), has been shown to possess anticarcinogenic, antiatherogenic [11, 14, 15], and immunomodulating activities, among other health benefits $[4,16]$. Recently, anti-tumoral activity has also been associated with butyric acid [4, 15-17].

The distribution of fatty acids in milk fat triacylglycerols is non-random, as indicated in Table 3. The majority of short-chain fatty acids $\mathrm{C} 4-\mathrm{C} 10$ are esterified in the primary positions ( $s n-1$ and $s n-3)$, while the middle position of the acylglycerol ( $s n-2)$ is mostly occupied by medium- and long-chain saturated fatty acids.

Most triacylglycerols contain 24-54 acyl carbon atoms. Due to this large variety of components, milk fat exhibits a large melting temperature range, between $-30^{\circ} \mathrm{C}$ and $37^{\circ}$ [1]. Therefore, both a solid and a liquid phase are present in the temperatures normally encountered during processing and use. The solid phase forms a fine network of small crystals, which traps and holds the liquid phase by surface

Table 2 Composition of lipid fraction in bovine milk [3]

\begin{tabular}{ll}
\hline Component & Content (wt\%) \\
\hline Triacylglycerols & $97-98$ \\
Diacylglycerols & $0.3-0.6$ \\
Monoacylglycerols & $0.02-0.04$ \\
Free fatty acids & $0.1-0.5$ \\
Cholesterol & $0.2-0.4$ \\
Phospholipids & $0.2-1.0$ \\
Carotene & $\mathrm{ppm}$ \\
Flavor compounds (lactones, aldehydes, ketones) & $\mathrm{ppm}$ \\
Vitamins A, D, and E & $\mathrm{ppm}$ \\
Tocopherol & $\mathrm{ppm}$ \\
\hline
\end{tabular}


Table 3 Milk fat fatty acid composition, in mol\% [11]

\begin{tabular}{lllcr}
\hline Fatty acid & Overall & \multicolumn{3}{c}{ Positional distribution } \\
\cline { 3 - 5 } & & $s n-1$ & $s n-2$ & $s n-3$ \\
\hline Butyric (C4) & 11.8 & 0 & 0 & 100 \\
Caproic (C6) & 4.6 & 0 & 7 & 93 \\
Caprylic (C8) & 1.9 & 25 & 12 & 63 \\
Capric (C10) & 3.7 & 17 & 27 & 56 \\
Lauric (C12) & 3.9 & 42 & 53 & 5 \\
Myristic (C14) & 11.2 & 29 & 52 & 19 \\
Palmitic (C16) & 23.9 & 47 & 45 & 8 \\
Hexadecenoic (C16:1) & 2.6 & 36 & 46 & 18 \\
Stearic (C18) & 7 & 49 & 45 & 6 \\
Oleic (C18:1) & 24 & 42 & 26 & 32 \\
Linoleic (C18:2) & 2.5 & 23 & 47 & 31 \\
\hline
\end{tabular}

tension. The network structure of the solid and liquid phase is responsible for the plasticity and consistency of the fat [18].

The milk fat globule membrane (MFGM) is composed of lipids and proteins, in a ratio of approximately $1: 1$ by weight. Butyrophilin (40\%) and xanthine oxidase $(12-13 \%)$ are the main proteic components of the MFGM [13], while the lipid components include triacylglycerols (66\%) and phospholipids (22\%), in particular sphingomyelin, phosphatidylcholine, and phosphatidylethanolamine [11]. Both the protein and lipids of the MFGM have been associated with a variety of positive health effects, including anticarcinogenesis, antidepressant, and bactericidal activity $[5,13]$.

\section{Milk fat revalorization}

The success of any consumer product depends on a good balance between price, perception, and performance [3]. Milk fat is perceived by the consumers as a natural, highquality product but its relatively high price compared to vegetable oils and fats hinders its consumption. On the other hand, the content of saturated fat and cholesterol still raises health concerns, although nowadays the weakness of the link established for many years between saturated fat consumption and hypercholesterolemia and cardiovascular disease is starting to be recognized $[4,16,19]$.

Saturated fats play a key role in providing structure to food. In this respect, one of the main drawbacks of milk fat is its limited functionality, related to the consistency of the fat at range of temperatures. For example, milk fat is too firm to spread easily at refrigeration, but not firm enough for certain pastry applications [6].

In the authors'opinion, the revalorization of milk fat implies finding applications in which other fats or oils cannot compete. For this purpose, the special qualities (flavor, texture, melting profile) or components (short-chain fatty acids, CLA, bioactive minor compounds) of milk fat have to be exploited.

Different approaches can be considered for the revalorization of milk fat:

- enhancing the nutritional or functional performance of milk fat, while maintaining its inherent qualities (milk fat engineering).

- producing added-value food or cosmetic ingredients by isolation or modification of major milk fat components

- isolating and commercializing the high-value minor components of milk fat

Hettinga [3] suggested that the success of milk fat revalorization relies on finding a large number of relatively small outlets for milk fat derivatives and/or innovative applications. This approach was applied with considerable success to the protein fraction of milk [3]. The health beneficial molecules of milk fat (MFGM components, CLA) could be isolated for commercialization or concentrated further in milk fat products. Although the potential commercial value of the minor components can be very high, only the usage of major components can lead to the reduction of butter stocks. Commercialization of minor components would however contribute to raising the value of milk fat, thus allowing using the major part of the fat in lower value applications.

Table 4 shows an overview of the different products and application fields of milk fat, milk fat fractions, and (potential) milk fat derivatives achieved either commercially or by different research groups around the world in recent years.

\section{Milk fat engineering}

Improving the performance of milk fat, both in nutritional and in physical terms (spreadability), is a promising area for research. Milk fat engineering concerns the modification of the fat structure or composition in order to achieve better properties of food products containing or composed of milk fat [1].

Currently, the major trends in milk fat engineering involve its physical or chemical modification, or altering the diet of the cow. Modification of the cow's diet, by introducing polyunsaturated oils or other dietary supplements, is a technique with relative success [5, 17]. Milk fat with a lower content of saturated fatty acids or enriched in CLA has been obtained from cows under special feeding regimes. For example, farmers in Ireland are producing milk for the manufacture of a naturally spreadable butter [5].

In the next paragraphs, only the "downstream" modification of milk fat (after separation from milk) will be discussed. 


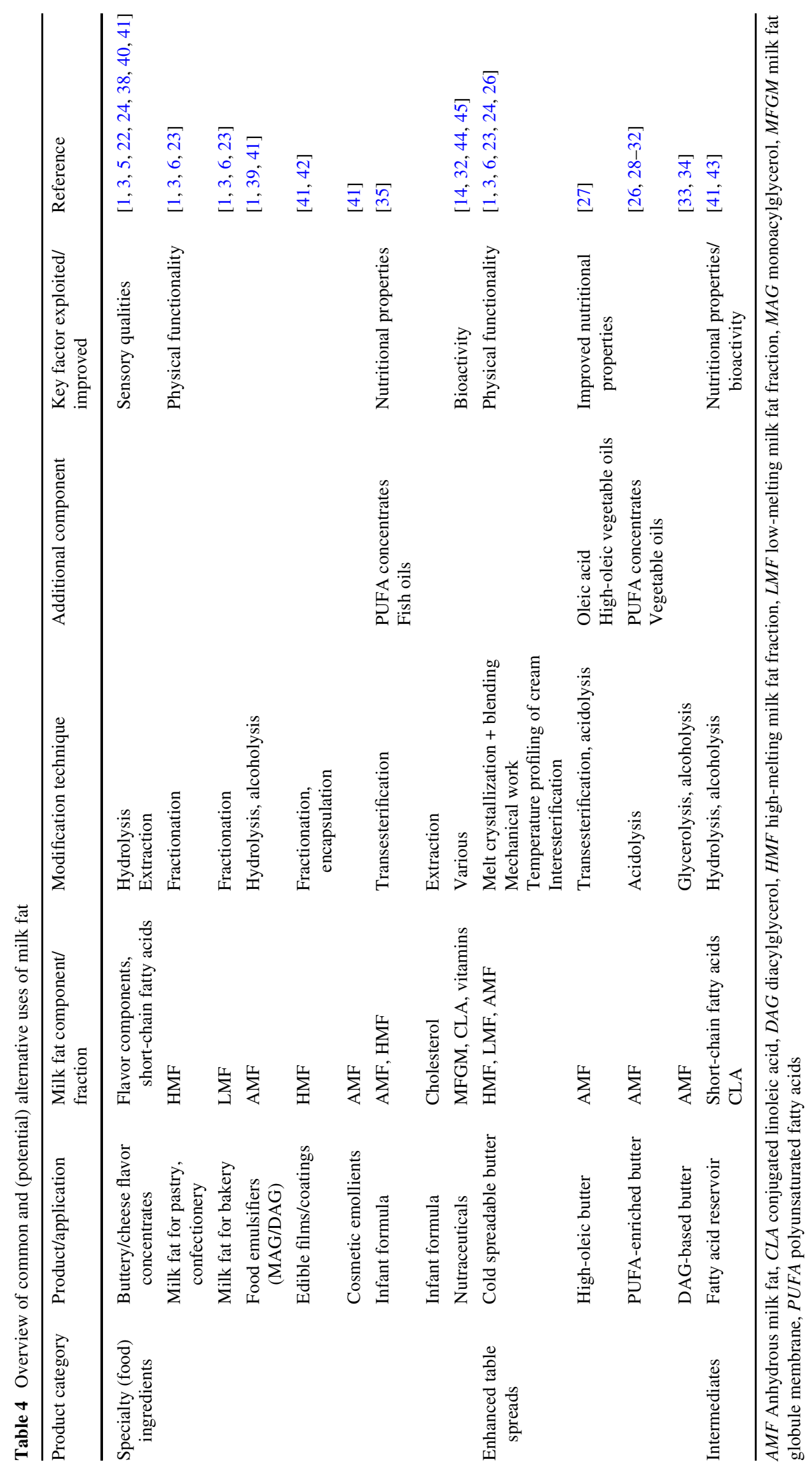


Physical modification Physical modification of milk fat involves mainly the improvement of spreadability [3]. This can be achieved by different techniques, including mechanical work (texturization), temperature profiling, blending with other oils, or fractionation [3, 6].

Fractionation consists of creating milk fat fractions with different melting point and crystallization patterns [1, 20]. Melt crystallization is the most developed fractionation technique, and it is widely applied commercially [3]. The low-melting and high-melting milk fat fractions produced by melt crystallization differ in the fatty acid composition of their triacylglycerols. Short-chain and unsaturated fatty acids predominate in the low-melting fractions and vice versa [21]. Short-path distillation and supercritical carbon dioxide fractionation have also been investigated. With these techniques, the separation is based on the difference in the molecular weight of triacylglycerols, rather than on their melting point differences [7, 22].

Nowadays, about 800 tonnes per day of milk fat is fractionated worldwide [23]. In general, all fractionation techniques yield milk fat fractions of similar functionality, but high-melting fractions that retain the flavor of milk fat can only be produced by melt crystallization [22]. Since short-, long-, saturated and unsaturated fatty acids are mixed in milk fat triacylglycerols, complete separation of fatty acid species is not possible by physical fractionation only.

Reduction of cholesterol was also an active area of research in the 1980s. However, it is nowadays recognized that the contribution of dietary cholesterol to coronary diseases is minor [1,3], which has decreased consumer demands for low-cholesterol products.

\section{Chemical or enzymatic modification Interesterification} using chemical catalysts results in a random rearrangement of the fatty acids in the triacylglycerols. This has an impact on the melting profile of milk fat, resulting in more spreadable products. However, the nutritional properties of the fat might be also affected by the rearrangement of fatty acids in the glycerol $s n$ positions [12]. In addition, the loss of the natural milk fat flavor in the process hinders the application of this technique $[3,24]$.

Lipase-catalyzed modification reactions are milder than chemically catalyzed reactions and have a lower tendency to affect the natural milk fat flavors. These have been mainly oriented to (a) releasing or concentrating flavor components by hydrolytic or transesterification reactions $[1,25]$ and (b) improving the nutritional properties of milk fat [24, 26-34]. From a nutritional point of view, the goal is generally reducing the content of the generally believed hypercholesterolemic saturated fatty acids (C12-C16) and/ or increasing the content of (poly)unsaturated fatty acids without altering the sensory properties of milk fat. To this end, several lipase-catalyzed (trans-) esterification reactions have been investigated. Some researchers found that lipasecatalyzed interesterification resulted in better spreadability of milk fat, but had the adverse effect of producing a waxlike mouthfeel [24]. Transesterification of milk fat with vegetable oils (soybean, rapeseed, corn) or with polyunsaturated fatty acid concentrates has been studied for producing physically or nutritionally enhanced spreads [26-32]. The obtained products were richer than milk fat in unsaturated fatty acids and also softer, spreadable at cold temperatures [26].

The natural structure of milk fat triacylglycerols, mostly containing a long-chain saturated fatty acid in the $s n-2$ position, makes it appropriate for the synthesis of human milk substitutes (HMS), by incorporation of polyunsaturated fatty acids in the $s n-1,3$ positions. This has been achieved by acidolysis using selective lipases [35].

Nevertheless, commercial production of interesterified or transesterified milk fat has not been realized so far. Milk and milk products enriched in oleic acid or PUFA exist in the market, but those are produced merely by blending with vegetable or fish oil concentrates. Lipase-catalyzed production of nutritionally improved oils and fats at industrial scale is limited to the production of structured lipids of vegetable origin, namely the human milk substitute Betapol@, cocoa butter replacers, and diacylglycerol-based oils [36-38]. The relatively high cost of specific lipases is still one of the major impediments for the development of such processes.

\section{Use of major components}

Butter and cheese flavor Production or isolation of buttery and cheese flavors is an existing field of milk fat utilization. Lipolyzed milk fat or milk fat fractions develop a stronger flavor. This is often an undesired effect, consequence of humidity in the fat. However, it can be applied to create a range of cheese flavors which can be incorporated to a variety of products. Established commercial applications can be found, in particular in the ice-cream and cheese industries [1, 24, 38]. Milk fat flavor has been isolated by extraction with supercritical carbon dioxide [40].

Mono- and diglycerides Mixtures of mono- and diacylglycerols are extensively used as emulsifiers in the food industry. MAG and DAG mixtures produced from milk fat are more hydrophilic than emulsifiers derived from other oils, because short-chain fatty acids are more polar than long-chain fatty acids. The hydrophilic/lipophilic balance of milk fat mono- and diacylglycerols can be useful for certain product applications [1, 38, 39]. The synthesis of a diacylglycerol-based milk fat analog with potentially enhanced nutritional properties has also been recently investigated [34]. 
Fatty acids Kaylegian [41] proposed the utilization of milk as fatty acid reservoir for the production of structured lipids (SL). Structured acylglycerols contain certain fatty acids in specific positions of the glycerol molecule, which gives them special nutritional properties. The short-chain fatty acid fraction of milk fat can be used for the synthesis of medium-chain triacylglycerols (indicated for parenteral and sports nutrition), low-caloric fats (triacylglycerols containing at least one short- and one long-chain fatty acid) [37], and short-chain sucrose polyesters to be used as fat substitutes [41]. Short-chain fatty acids for the synthesis of SL are currently obtained from coconut oil fractions containing C8-C10 fatty acids or synthetically. Milk fat, with its relatively high content of C4-C10 fatty acids, appears therefore as an interesting fatty acid source for the production of SL. Recent work by the authors reports the development of a process making integrated use of lipase-catalyzed ethanolysis and supercritical carbon dioxide extraction for the isolation of a short-chain fatty acid concentrate from milk fat [42].

\section{Use of minor components}

\section{Components of the milk fat globule membrane (MFGM)}

Ongoing research exists for isolating the bioactive proteins and lipids of the MFGM [5, 44]. Micro- and ultrafiltration, coagulation, and solvent- or supercritical extraction are being investigated. The raw material used is often buttermilk, where the MFGM molecules are most concentrated [44]. Isolated components of MFGM could be used in the pharmaceutical industry or incorporated as nutraceutical ingredients in food products.

Conjugated linolenic acid (CLA) Some research has been oriented to the development of techniques for concentrating conjugated linolenic acid (CLA) in milk fat, including transesterification with CLA concentrates [32] or supercritical fluid fractionation [45]. However, the resulting enrichment in CLA was relatively low and does not seem to be economically justified. A more promising approach for increasing CLA content in milk fat has been altering the diet of the cow, by incorporation of dietary supplements based on fish oils [5].

Cholesterol Cholesterol, despite not recommended in adult diets, is an important molecule for the infant brain development, and as such, it is suitable for being incorporated in infant food formulations. Cholesterol removed from milk fat can be utilized in this way. At the same time, the cholesterol-free milk fat obtained on the other hand has an increased value as well. Several methods exist for removing cholesterol from milk fat: steam stripping, shortpath distillation, absorption, extraction, and enzymatic techniques [3]. Absorption using cyclodextrines has been commercially applied for producing low-cholesterol cheese and butter, although resulting in relatively expensive products.

\section{Conclusions}

Despite the promising results on many research areas, the production and utilization of milk fat derivatives is nowadays limited to the production of flavors and milk fat fractions. A great potential exists therefore for the development and commercialization of a variety of innovative, addedvalue products, which would contribute to the reduction of the butter stocks and the overall revalorization of milk fat.

Acknowledgments SenterNovem (Ministry of Economic Affairs, the Netherlands) is gratefully acknowledged for the financial support of this work.

Open Access This article is distributed under the terms of the Creative Commons Attribution Noncommercial License which permits any noncommercial use, distribution, and reproduction in any medium, provided the original author(s) and source are credited.

\section{References}

1. Balcao VM, Malcata FX (2002) Enzyme-mediated modification of milkfat. In: Kuo TM, Gardner HW (eds) Lipid biotechnology. Marcel Dekker, New York

2. Huppertz T, Kelly AL, Fox PF (2009) Milk lipids-Composition, origin and properties. In: Tamime AY (ed) Dairy fats and related products. Wiley, Oxford

3. Hettinga D (2005) Butter. In: Shahidi F (ed) Bailey's industrial oil and fat products, vol 2, 6th edn. Hoboken-Wiley Interscience, Hoboken

4. Parodi PW (2009) Milk fat nutrition. In: Tamime AY (ed) Dairy fats and related products. Wiley, Oxford

5. Hillbrick G, Augustin MA (2002) Milkfat characteristics and functionality: opportunities for improvement. Aust J Dairy Technol 57:45-51

6. Kaylegian KE, Hartel RW, Lindsay RC (1993) Application of modified milk fat in food products. J Dairy Sci 76:1782-1796

7. Augustin MA, Versteeg C (2006) Milk fat: physical, chemical and enzymatic modification. In: Fox PF, McSweeney PLH (eds) Advanced dairy chemistry, vol. 2, 3rd edn. Springer Science, New York

8. Illingworth D, Patil GR, Tamime AY. Anhydrous milk fat manufacture and fractionation. In: Tamime AY (ed) Dairy fats and related products. Wiley, Oxford

9. Milk and milk products in the European Union (2006) European comission directorate-general for agricultural and rural development. Office for Official Publications of the European Communities, Luxembourg

10. EU Dairy production and market balances (2010) DairyCo datum, Kenilworth. http://www.dairyco.net/datum. Accessed October 2010

11. Jensen RG, Ferris AM, Lammi-Keefe CJ (1991) The composition of milk fat. J Dairy Sci 47:3228-3243

12. Jensen RG (2002) The composition of bovine milk lipids: jan 1995 to Dec 2000. J Dairy Sci 85:295-350 
13. Spitsberg VL (2005) Bovine milk fat globule membrane as a potential nutraceutical. J Dairy Sci 88:2289-2294

14. Singh H (2006) The milk fat globule membrane-a biophysical system for food applications. Curr Opin Colloid Interface Sci 11:154-163

15. Akalin S, Gonc S, Unal G (2006) Functional properties of bioactive components of milk fat in metabolism. Pak J Nutr 5:194-197

16. Parodi PW (2006) Nutritional significance of milk lipids. In: Fox PF, McSweeney PLH (eds) Advanced dairy chemistry, vol. 2, 3rd edn. Springer Science, New York

17. Henning DR, Baer RJ, Hassan AN, Dave R (2006) Major advances in concentrated and dry milk products, cheese, and milk fat-based spreads. J Dairy Sci 89:1179-1188

18. Walstra P, Kloek W, van Vliet T (2001) Fat crystal networks. In: Garti N, Sato K (eds) Crystallization processes in fat and lipid systems. Marcel Dekker, New York

19. Westman EC (2009) Rethinking dietary saturated fats. Lipid Technol 21:109-111

20. Wright AM, Scanlon MA, Hartel RW, Marangoni AG (2001) Rheological properties of milk fat and butter. J Food Sci 66: 1056-1071

21. Lopez C, Bourgau C, Lesieur P, Riaublan A, Ollivon M (2006) Milk fat and primary fractions obtained by dry fractionation 1 . Chemical composition and crystallisation properties. Chem Phys Lipids 144:17-33

22. Boudreau A, Arul J (1993) Cholesterol reduction and fat fractionation technologies for milk fat. A review. J Dairy Sci 76:1772-1781

23. Deffense E (1993) Milk fat fractionation today. A review. J Am Oil Chem Soc 70:1193-1201

24. De Greyt W, Huyghebaert A (1995) Lipase-catalyzed modification of milk fat. Lipid technol 1:10-12

25. Lubary M, ter Horst JH, Hofland GW, Jansens PJ (2009) Lipase catalyzed ethanolysis of milk fat with a focus on short-chain fatty acid selectivity. J Agric Food Chem 57:116-121

26. Marangoni AG, Rousseau D (1998) Chemical and enzymatic modification of butterfat and butterfat-canola oil blends. Food Res Int 31:595-599

27. Balcao VM, Kempinnen A, Malcata FX, Kaalo PJ (1998) Lipasecatalyzed acidolysis of butterfat with oleic acid: characterization of process and product. Enzyme Microb Tech 23:118-128

28. Caponio F, Alloggio V, Pallavicini C (1998) Modification of goat milk fat triglycerides by immobilized lipase. Fett/Lipid 100:74-78

29. Pal PK, Bhattacharyya DK, Ghosh S (2001) Modifications of butter stearin by blending and interesterification for better utilization in edible fat products. J Amer Oil Chem Soc 78:31-36

30. Ronne TH, Yang T, Mu H, Jacobsen C, Xu X (2005) Enzymatic interesterification of butterfat with rapeseed oil in a continuous packed bed reactor. J Agric Food Chem 53:5617-5624
31. Aguedo M, Hanon E, Danthine S (2008) Enrichment of anhydrous milk fat in polyunsaturated fatty acid residues from linseed and rapeseed oils through enzymatic interesterification. J Agric Food Chem 56:1757-1765

32. Garcia HS, Storkson JM, Pariza MW, Hill CG (1998) Enrichment of butteroil with conjugated linoleic acid via enzymatic interesterification (acidolysis) reactions. Biotechnol Lett 20:393-395

33. Yang T, Zhang H, Mu H, Sinclair AJ, Xu X (2004) Diacylglycerols from butterfat. Production by glycerolysis and short-path distillation and analysis of physical properties. J Amer Oil Chem Soc 81:979-987

34. Lubary M, Hofland GW, ter Horst JH (2010) A process for the synthesis of a diacylglycerol-based milk fat analogue. Eur J Lipid Sci Tech, Accepted for publication

35. Christensen TC, Holmer G (1993) Lipase-catalyzed acyl exchange reactions of butter oil. Synthesis of a human milk fat substitute for infant formulas. Milchwissenschaft 48:543-548

36. Kristensen JB, Xu X, Mu H (2005) Diacylglycerol synthesis by enzymatic glycerolysis. Screening of commercially available lipases. J Amer Oil Chem Soc 82:329-334

37. Xu X (2000) Production of specific-structured triacylglycerols by lipase-catalyzed reactions. A review. Eur J Lipid Sci Techn 102:287-303

38. Alloue WAM, Aguedo M, Destain J, Ghalfi H, Blecker C, Whatelet JP, Thonart P (2008) Immobilized lipases and their applications. Biotechnol Agron Soc Envir 12:57-68

39. Campbell-Timperman K, Choi JH, Jimenez-Flores R (1996) Mono- and diglycerides prepared by chemical glycerolysis from a butterfat fraction. J Food Sci 61:44-47

40. de Haan AB (1991) Supercritical fluid extraction of hydrocarbon mixtures. PhD Thesis, Delft University of Technology, Delft

41. Kaylegian KE (1994) Functional characteristics and nontraditional applications of milk lipid components in food and nonfood systems. J Dairy Sci 78:2524-2540

42. Audic JL, Chaufer B, Daufin G (2003) Non-food applications of milk components and dairy co-products: a review. Lait 83: 417-438

43. Lubary M, ter Horst JH, Hofland GW, Jansens PJ (2010) Integrated synthesis and extraction of short-chain fatty acid ethyl esters by supercritical carbon dioxide. AIChE J 56:1080-1089

44. Rombaut R, Dewettink K (2006) Properties, analysis and purification of milk polar lipids. Int Dairy Journal 11:1362-1373

45. Romero P, Rizvi SSH, Kelly ML, Bauman DE (2000) Concentration of conjugated linoleic acid from milk fat with a continuous supercritical fluid processing system. J Dairy Sci 83:20-22 